\title{
Double Dens Invaginatus: Report of Three Cases
}

\author{
A. Zeynep Zengin ${ }^{a}$ \\ A. Pinar Sumer ${ }^{\text {b }}$ \\ Peruze Celenk ${ }^{c}$
}

\section{ABSTRACT}

Dens invaginatus results from an infolding of the outer surface of a tooth. The clinical importance of dens invaginatus results from the risk of pulpal disease. So, all clinicians should be aware of this anomaly. The presence of double dens invaginatus is extremely rare. This article presents three cases of double dens invaginatus in permanent maxillary lateral incisors, one with preventive restoration on its palatal surface. They were classified as double dens invaginatus because of two enamel lined invaginations presented in the crowns of these teeth. (Eur J Dent 2009;3:67-70)

Key words: Double dens invaginatus; Dens in dente; Abnormalities in teeth.

\section{INTRODUCTION}

Dens invaginatus known also as dens in dente from the literature is a developmental anomaly resulting from invagination of enamel organ into the dental papilla, beginning at the crown and sometimes extending into the root before calcification occurs. ${ }^{1,2}$ It commonly occurs in maxillary permanent lateral incisors followed by

- a Research Assistant, Department of Oral Diagnosis and Radiology, Faculty of Dentistry, University of Ondokuz Mayis, Samsun, Turkey.

${ }^{b}$ Assistant Professor, Department of Oral Diagnosis and Radiology, Faculty of Dentistry, University of Ondokuz Mayis, Samsun, Turkey. c Professor, Department of Oral Diagnosis and Radiology, Faculty of Dentistry, University of Ondokuz Mayis, Samsun, Turkey.

Corresponding author: A. Zeynep Zengin Ondokuz Mayis Universitesi, Dis Hekimligi Fakultesi Oral Diagnoz ve Radyoloji Anabilim Dali 55139 Kurupelit, Samsun, Turkey. Phone: +90 362 3121919-3012 Fax: +90 3624576032 E-mail: dtzeynep78ahotmail.com the maxillary central incisors, premolars, canines and less often in the molars. ${ }^{1}$

Clinically, dens invaginatus appears in the tooth crown at the site of an anatomical lingual pit susceptible to caries. ${ }^{3}$ Radiographically, it shows a radiopaque invagination, equal in density to enamel, extending from the cingulum into the root canal. ${ }^{1}$ The defects may vary in size and shape from a loop like, pear-shaped or slightly radiolucent structure to a severe form resembling a "tooth within a tooth". ${ }^{4}$ It can be identified easily because infolding of the enamel lining is more radiopaque than the surrounding tooth structure. ${ }^{1}$

Oehlers ${ }^{5}$ described dens in dente according to invagination degree in three forms:

Type 1: an enamel-lined minor form occurs within the crown of the tooth and not extending beyond the cemento-enamel junction;

Type 2: an enamel-lined form which invades the root as a blind sac and may communicate 
with the dental pulp;

Type 3: a severe form which extends through the root and opens in the apical region without communicating with the pulp.

Double dens invaginatus is an extremely rare dental anomaly involving two enamel lined invaginations presented in the crowns or roots of a tooth. This article reports three cases of double dens invaginatus in maxillary lateral incisors.

\section{CASE 1}

A 20 year old woman reported to our clinic for orthodontic treatment. The patient was in good general health. Extraoral examination revealed no significant findings. Intraorally the gingiva was inflamed. The maxillary left lateral permanent incisor was found to have an abnormal crown form with restoration. On the palatal surface, lingual cingulum was joined to the labial cusp by a prominent transverse ridge resembling an extra cusp was present which divided the palatal surface into two fossae. Two palatal pits was located and had restored in each fossae. On radiographic examination of the maxillary left lateral incisor, two dens invaginatus were presented originating from each palatal pit (Figure 1). The tooth had a single root, was vital, and no evidence of periapical infection was noted.

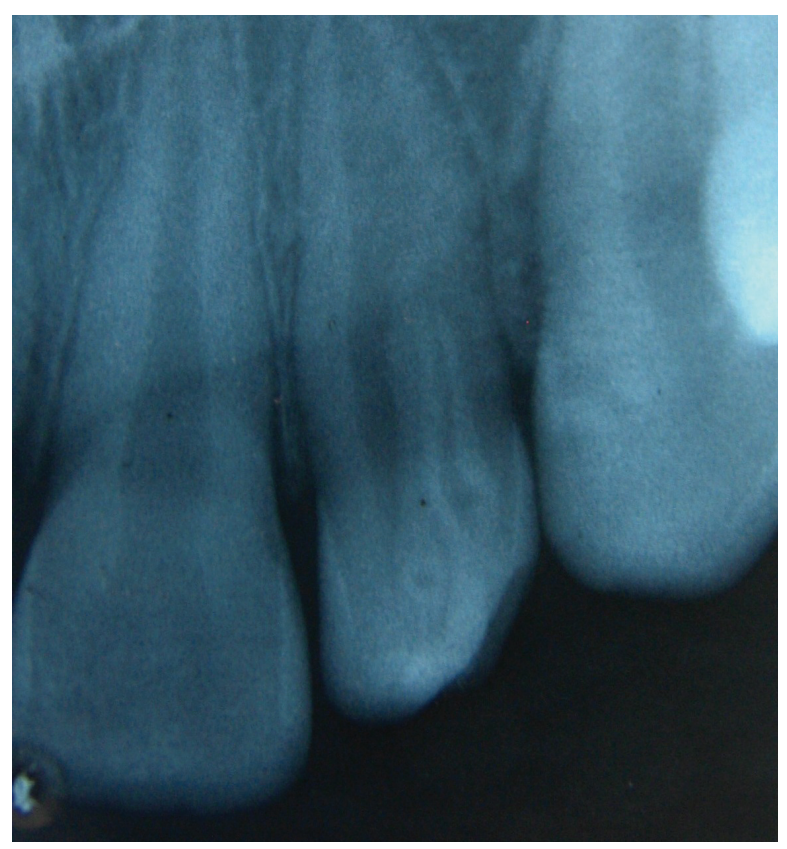

Figure 1. Periapical radiograph showing a restorated maxillary left lateral incisor with double dens invaginatus.

\section{CASE 2}

22 year old woman reported to our clinic for a routine dental treatment. The patient was in good general health. Extraoral examination revealed no significant findings. Intraoral examination, showed a deep anatomic pit on palatal surface of maxillary left lateral permanent incisor. In periapical radiograph two dens invaginatus were seen (Figure 2). The patient had no associated symptoms, and there were no radiographically visible lesions associated with the affected tooth. The tooth appeared healthy and was vital. The patient was referred for restoration of the palatal pit to avoid possible infection.

\section{CASE 3}

A 35 year old woman reported to our clinic complaining of pain in the maxillary right central incisor. The patient was in good general health. Extraoral examination revealed no significant findings. In intraoral examination a maxillary right lateral incisor with an abnormal crown form was observed. Radiographic examination showed two dens invaginati extending to the root originating from two pits of lateral incisor (Figure 3). The tooth tested vital with electric pulp sensitivity testing and had no periapical lesion radiographically. The patient was referred for endodontic treatment of her maxillary right

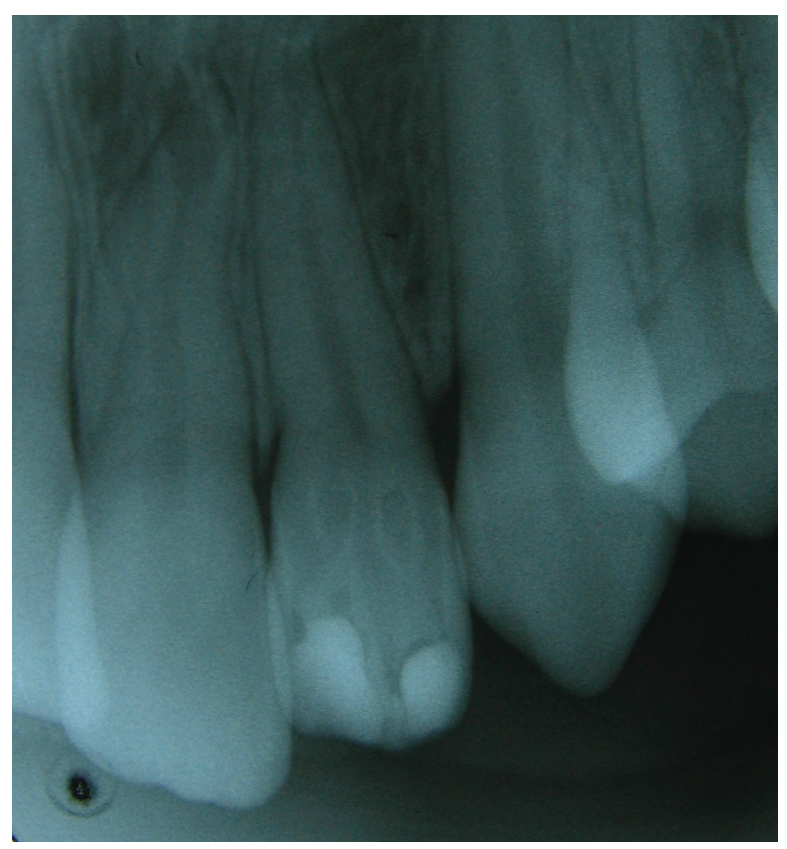

Figure 2. Periapical radiograph showing a maxillary left lateral incisor with double dens invaginatus. 
central incisor and prophylactic restoration of the palatal pits of maxillary right lateral incisor.

\section{DISCUSSION}

Dens invaginatus is clinically important due to the possibility of the pulp being affected. Because of the lingual anatomy, it is possible for dental caries to easily reach the pulp chamber. ${ }^{6}$ The patient is usually detected by chance with the help of intraoral periapical radiographs. ${ }^{7}$ All the patients reported here were asymptomatic and unaware of this condition.

Upon radiographic evidence of dens invaginatus, the apical periodontium should be examined because fine channels or cracks may run between the invagination and the pulp. Microorganisms may pass from oral cavity through dens invaginatus into the pulp. Therefore, pathosis eventually occurs at the apical area. ${ }^{3}$ If the radiographic appearance is unremarkable, pulp vitality testing should be performed. If the results suggest vital and unaffected pulpal tissue, then the teeth should be promptly restored to curtail access of dens invaginatus to the oral environment. ${ }^{6}$ All teeth reported here were vital and no evidence of periapical infection was noted. In the first case, the tooth had been already restorated with composite resin restoration. In other two cases the teeth needed prophylactic restoration. The management of dens invaginatus with pulpal involvement varies from conventional

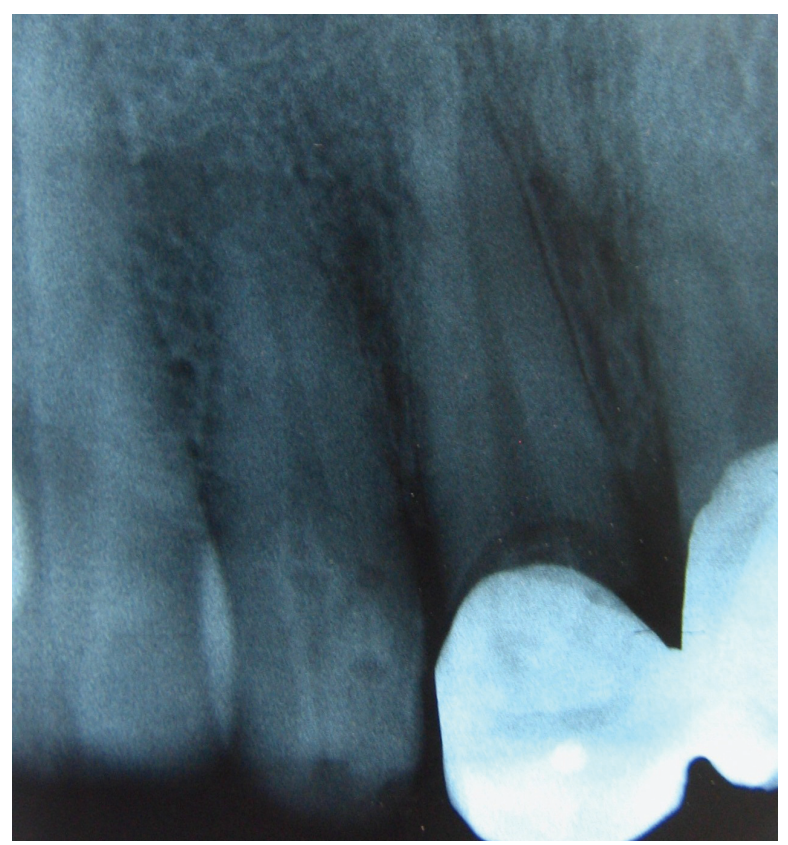

Figure 3. Periapical radiograph showing a maxillary right lateral incisor with double dens invaginatus. endodontic treatment, ${ }^{3}$ to special endodontic techniques capable of inducing an apexification. ${ }^{8}$ Thomas $^{9}$ has recommended prophylactic restoration of tooth with dens invaginatus at ages 7 to 14 .

There are several reports of dens in dente associated with other abnormalities such as taurodontism, microdontia, gemination, supernumerary tooth and dentinogenesis imperfecta. 3,10 The cases reported here had no other abnormalities. According to Oehlers ${ }^{5}$ description in invagination degree of first case and one of dens invaginatus of the second and third case was "type 1" because invagination cavities were not extending beyond the cementoenamel junction. But the other dens invaginatus of second and third case were type 2, as the large invagination extending towards the root.

Dens invaginatus is relatively common dental anomaly. In a review of the literature by Pindborg ${ }^{11}$ the prevelance of dens invaginatus affecting the maxillary lateral incisors ranges from $0.25 \%$ to $5.1 \%$. However, few cases of double dens invaginatus in a single tooth have been reported. 3,12,13 According to Mupparapu ${ }^{14}$ only 9 cases of double dens invaginatus have been reported.

\section{CONCLUSIONS}

This report presents three cases of double dens invaginatus in permanent maxillary lateral incisors. The clinician should be aware of this anomaly because of the risk of apical inflammatory disease. Prophylactic restoration of the palatal pits of these teeth is important to avoid possible biologic injury and related inflammation.

\section{REFERENCES}

1. White SC, Pharoah MJ. Oral radiology principles and interpretation $4^{\text {th }}$ ed. St Louis, Mosby, 2000, pp. 314-315.

2. Lee AM, Bedi R, O'Donnell D. Bilateral double dens invaginatus of maxillary incisors in a young Chinese girl. Aust Dent $J$ 1988;33:310-312.

3. Vajrabhaya L. Nonsurgical endodontic treatment of a tooth with double dens in dente. J Endod 1989;15:323-325.

4. Gotoh T, Kawahara K, Imai K, et al. Clinical and radiographic study of dens invaginatus. Oral Surg Oral Med Oral Pathol 1979;48:88-91.

\section{January 2009 - Vol.3}


5. Oehlers FAC. Dens invaginatus /dilated composite odontoma). 1. Variations of the invagination process and associated anterior crown forces. Oral Surg Oral Med Oral Pathol 1957;10:1204-1218.

6. Mupparapu M, Singer SR. A rare presentation of dens invaginatus in a mandibular lateral incisor occurring concurrently with bilateral maxillary dens invaginatus: case report and review of literature. Aust Dent J 2004;49:9093.

7. Yeh SC, Lin YT, Lu SY. Dens invaginatus in the maxillary lateral incisor: treatment of 3 cases. Oral Surg Oral Med Oral Pathol Oral Radiol Endod 1999;87:628-631.

8. Schindler WG, Walker WA 3rd. Continued root development after apexification of an immature tooth with dens invaginatus. J Endod 1983;9:430-433.

9. Thomas JG. A study of dens in dente. Oral Surg Oral Med Oral Pathol 1974;38:653-655.

10. Ireland EJ, Black JP, Scures CC. Sort roots, taurodontia and multiple dens invaginatus. J Pedod 1987;11:164-175.

11. Pindborg JJ. Pathology of the Dental Hard Tissues Philadelphia. WB Saunders, 1970, pp. 58.

12. Suprabha BS. Premolarized double dens in dente in albinism- A case report. J Indian Soc Pedod Prev Dent 2005;23:156-158.

13. Noikura T, Ooya K, Kikuchi M. Double dens in dente with a central cusp and multituberculism in bilateral maxillary supernumerary central incisors. Report of a case. Oral Surg Oral Med Oral Pathol Oral Radiol Endod 1996;82:466-469.

14. Mupparapu M, Singer SR, Pisano D. Diagnosis and clinical significance of dens invaginatus to practicing dentists. $N Y$ State Dent J 2006;72:42-46. 